\title{
Biology of Cholangiocytes: From Bench to Bedside
}

\author{
Kyo-Sang Yoo ${ }^{1}$, Woo Taek $\mathrm{Lim}^{2}$, and Ho Soon $\mathrm{Choi}^{1}$ \\ ${ }^{1}$ Department of Internal Medicine, Hanyang University College of Medicine, and ${ }^{2}$ Korea University School of Medicine, Seoul, Korea
}

Cholangiocytes, the lining epithelial cells in bile ducts, are an important subset of liver cells. They are activated by endogenous and exogenous stimuli and are involved in the modification of bile volume and composition. They are also involved in damaging and repairing the liver. Cholangiocytes have many functions including bile production. They are also involved in transport processes that regulate the volume and composition of bile. Cholangiocytes undergo proliferation and cell death under a variety of conditions. Cholangiocytes have functional and morphological heterogenecity. The immunobiology of cholangiocytes is important, particularly for understanding biliary disease. Secretion of different proinflammatory mediators, cytokines, and chemokines suggests the major role that cholangiocytes play in inflammatory reactions. Furthermore, paracrine secretion of growth factors and peptides mediates extensive cross-talk with other liver cells, including hepatocytes, stellate cells, stem cells, subepithelial myofibroblasts, endothelial cells, and inflammatory cells. Cholangiopathy refers to a category of chronic liver diseases whose primary disease target is the cholangiocyte. Cholangiopathy usually results in end-stage liver disease requiring liver transplant. We summarize the biology of cholangiocytes and redefine the concept of cholangiopathy. We also discuss the recent progress that has been made in understanding the pathogenesis of cholangiopathy and how such progress has influenced therapy. (Gut Liver 2016;10:687-698)

Key Words: Cholangiocyte; Biology; Cholangiopathy; Transport; Receptors

\section{INTRODUCTION}

The biliary system is comprised of intrahepatic bile ducts, extrahepatic bile ducts and the gallbladder. Bile is transported by the extensive biliary tract, which measures approximately $2 \mathrm{~km}$ in human. A layer of epithelial cells called cholangiocytes lines the intrahepatic bile ducts of this extensive network. The extrahepatic ductal epithelial cells and gallbladder epithelial cells (GBECs) share many features with cholangiocytes. Cholangiocytes comprise only about 3\% to 5\% of the total cell mass of the liver, but they are crucial for normal physiologic processes, and they contribute to multiple disease states of the biliary tract. ${ }^{1-5}$

Cholangiocytes serve several functions performed by several important molecules. Most importantly, cholangiocytes participate in the formation and transportation of bile via transmembrane molecules that are expressed on the apical or basolateral membrane. These transporters include channels (i.e., water channels [aquaporins]), transporters (i.e., SGLT1: $\mathrm{Na}^{+}$-glucose transporter), and exchangers (i.e., SLC4A2: $\mathrm{Cl}^{-} / \mathrm{HCO}_{3}{ }^{-}$exchanger). Impairing these molecules could lead to cholestasis (Fig. 1). ${ }^{6-8}$ Cholangiocytes also interact with resident and nonresident cells of the bile ducts via inflammatory and fibrotic mediators, such as tumor necrosis factor $\alpha$ (TNF- $\alpha$ ) and interleukin 6 (IL-6). On the other hand, diseased cholangiocytes can cause biliary inflammation and fibrosis. Finally, cholangiocytes are involved in cell-cycle phenomena that maintain tissue homeostasis in the biliary system via modulators of apoptosis (i.e., AkT1: protein kinase $B \alpha$ ), senescence (i.e., N-RAS transforming protein), and proliferation (i.e., platelet-derived growth factor). Damage to the cholangiocytes may result in ductopenia, dysplasia, or malignant transformation of the bile ducts (Fig. 2). ${ }^{6-8}$

Unlike other epithelial cells, cholangiocytes are morphologically and functionally heterogeneous., ${ }^{90}$ Small cholangiocytes possess proliferative capabilities and display functional plasticity in disease, while large cholangiocytes are involved in hormoneregulated bile secretion. Stem cells in the peribiliary glands that can differentiate into cholangiocytes may be involved in biliary remodeling and pathogenesis of cholangiopathies. ${ }^{11,12}$ Understanding the biology of cholangiocytes allows us to understand the mechanisms of cholangiopathy (Fig. 2) and to develop ad-

\footnotetext{
Correspondence to: Ho Soon Choi

Department of Internal Medicine, Hanyang University College of Medicine, 222 Wangsimni-ro, Seongdong-gu, Seoul 04763, Korea

Tel: +82-2-2290-8379, Fax: +82-2-2298-9183, E-mail: hschoi96@hanyang.ac.kr

Received on January 19, 2016. Revised on February 14, 2016. Accepted on March 9, 2016.

pISSN 1976-2283 eISSN 2005-1212 http://dx.doi.org/10.5009/gnl16033

(a) This is an Open Access article distributed under the terms of the Creative Commons Attribution Non-Commercial License (http://creativecommons.org/licenses/by-nc/4.0) which permits unrestricted non-commercial use, distribution, and reproduction in any medium, provided the original work is properly cited.
} 

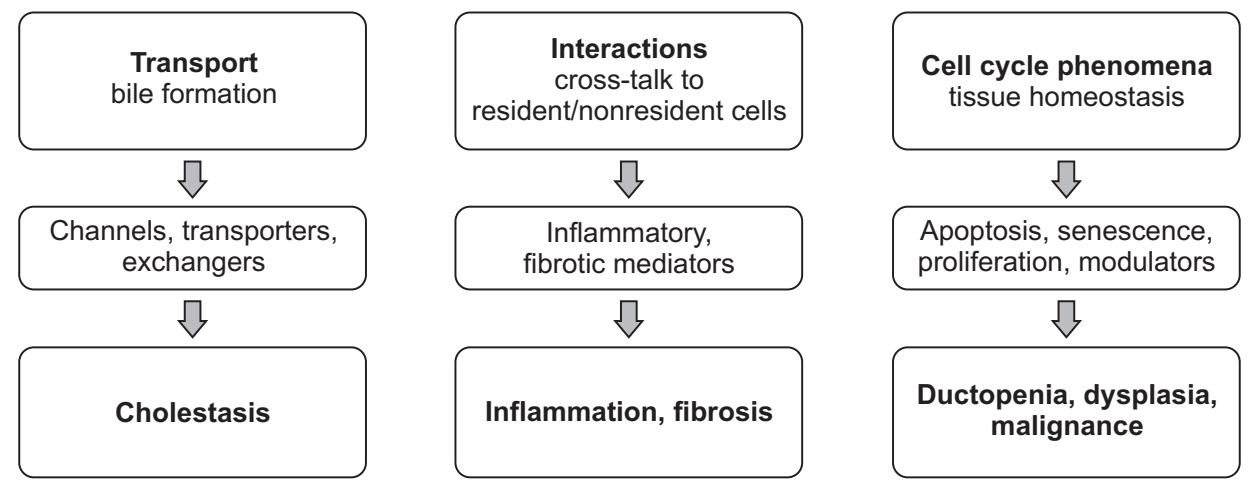

Fig. 1. Biology of cholangiocytes. ${ }^{6,743,44}$ Various molecules conduct several important functions in cholangiocytes. Bile is formed through the activity of transmembrane molecules, such as channels, transporters, and exchangers. Dysfunction of these molecules may lead to cholestasis. Cholangiocytes interact with resident and nonresident cells of bile ducts via inflammatory and fibrotic mediators, such as tumor necrosis factor $\alpha$ and interleukin 6, which, in disease states, results in biliary inflammation and fibrosis. Cholangiocytes contribute to the cell-cycle phenomena that maintain tissue homeostasis via modulators of apoptosis, senescence, and proliferation. In disease states, these processes may result in ductopenia, dysplasia, and malignant transformation of the bile ducts.

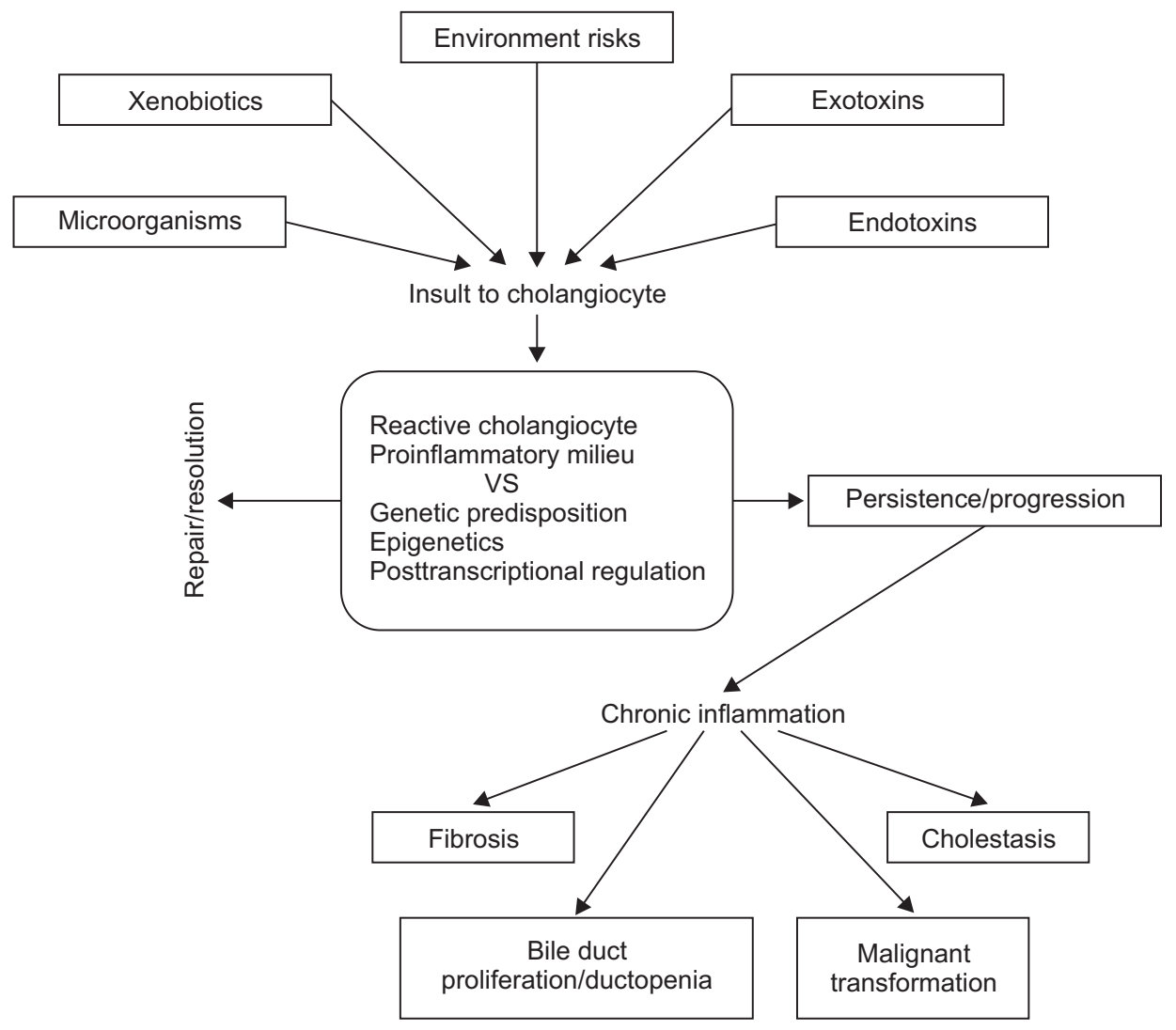

Fig. 2. Pathogenic model of cholangiopathy. ${ }^{6,73,44}$ Cholangiocytes interact with endogenous or exogenous substances, microorganisms, or environmental factors. The initial host response is the development of a reactive cholangiocyte and a proinflammatory microenvironment. The balance of the host response to insult depends on genetic susceptibility, epigenetics, and posttranscriptional regulation, and it may result in the resolution of the disease state or the perpetuation of the initial inflammatory response. This may result in chronic inflammation of the bile ducts and ultimately to cholestasis, bile duct proliferation, ductopenia, fibrosis, and the potential malignant transformation of cholangiocytes.

equate treatment for these diseases.

Findings from electron microscopy of cholangiocytes show the apical microvilli facing the lumen of the bile duct and various micro-organelles, such as the rough endoplasmic reticulum, mitochondria, vesicles, and nucleus in cytoplasm. From such findings, we can speculate that cholangiocytes are incredibly versatile and complex in their functions. The cholangiocyte indeed has many functions, which can be categorized into four broad areas. Firstly, cholangiocytes are involved in transport processes that regulate the volume and composition of bile. 
Secondly, cholnagiocytes undergo proliferation and cell death under a variety of conditions, some of which are important in our understanding of disease states. Thirdly, the concept of cholangiocyte heterogeneity has attracted attention, as not all cholangiocytes are functionally or morphologically identical. Finally, the immunobiology of the cholangiocyte is important for understanding diseases characterized by vanishing bile ducts, such as primary biliary cirrhosis (PBC), primary sclerosing cholangitis (PSC), allograft rejection, and graft-versus-host disease (GVHD). ${ }^{1-4,13,14}$

\section{CHOLANGIOPATHY}

Based on the importance of cholangiocytes in normal hepatobiliary physiology emerged the idea of cholangiopathy-a disease state that is characterized by abnormalities in cholangio- cyte function. Cholangiopathy can be generally classified into immune-mediated states (some of which are characterized by the vanishing bile duct syndromes), infectious, genetic, idiopathic, malignant, and secondary sclerosing cholangitis (Table 1). ${ }^{6}$ To understand the variety in cholangiopathy, a review of cholangiocyte biology is crucial. ${ }^{1,4,5,15-18}$

Each type of cholangiopathy has a unique manifestation and clinical course, yet they share common processes that involve proinflammatory signaling, innate immune responses, cholangiocyte proliferation and differentiation, as well as tissue repair processes. $^{6}$

Cholangiocytes are activated by various insults, which then increase expression of proinflammatory cytokines and chemokines (e.g., IL-6, IL-8, TNF- $\alpha$, and various growth factors). ${ }^{19}$ The released molecules act in autocrine and paracrine manners, and ultimately lead to cholangiocyte proliferation, apoptosis,

Table 1. Classification of Cholangiopathy ${ }^{1,6}$

\begin{tabular}{|c|c|}
\hline Immune mediated & Idiopathic or immune mediated \\
\hline Hepatic allograft rejection & Autoimmune cholangitis \\
\hline GVHD & Biliary atresia* \\
\hline PBC & Idiopathic childhood/adulthood ductopenia \\
\hline Autoimmune cholangitis & IgG4-associated cholangitis \\
\hline \multirow[t]{2}{*}{ PSC } & $\mathrm{PBC}^{*}$ \\
\hline & $\mathrm{PSC}^{*}$ \\
\hline Infectious & Malignant \\
\hline Viral (incl. HIV-associated cholangitis) & Cholangiocarcinoma \\
\hline \multicolumn{2}{|l|}{ Bacterial } \\
\hline \multicolumn{2}{|l|}{ Fungal } \\
\hline \multicolumn{2}{|l|}{ Parasitic } \\
\hline \multicolumn{2}{|l|}{ Protozoan } \\
\hline Genetic & Secondary sclerosing cholangitis \\
\hline Alagille syndrome & ABCB4 deficiency \\
\hline Caroli syndrome & Abdominal trauma (surgical or blunt) \\
\hline Cystic fibrosis & AIDS cholangiopathy \\
\hline Polycystic liver disease & Amyloidosis \\
\hline ADPLD & Chemical/drugs (i.e., 5-fluorouracil) \\
\hline ADPKD & Choledocholithiasis \\
\hline \multirow[t]{8}{*}{ ARPKD } & Eosinophilic or mast cell cholangitis \\
\hline & GVHD involving the liver \\
\hline & Iatrogenic biliary strictures \\
\hline & Portal hypertensive biliopathy \\
\hline & Recurrent pyogenic cholangitis \\
\hline & Sarcoidosis \\
\hline & Sickle cell disease \\
\hline & Vascular/ischemic (i.e., hepatic artery stenosis after liver transplant) \\
\hline
\end{tabular}

GVHD, graft-versus-host disease; PBC, primary biliary cirrhosis; PSC, primary sclerosing cholangitis; HIV, human immunodeficiency virus; ADPLD, autosomal dominant polycystic liver disease; ADPKD, autosomal dominant polycystic kidney disease; ARPKD, autosomal recessive polycystic kidney disease; ABCB, ATP-binding cassette transporter B; AIDS, acquired immunodeficiency syndrome.

*For the genetic component of these diseases. 
senescence, angiogenesis, fibrosis, and the recruitment of innate and adaptive immune cells, mesenchymal cells, and endothelial cells. Such events result in ductal reactions such as proliferation of ductules, infiltration of leukocytes and lymphocytes, activation of liver progenitor cells, and an increase in matrix protein. Eventually, these events result in periportal fibrosis, ductopenia, and biliary cirrhosis (Fig. 2). ${ }^{6,20}$

The initial host response to various insults is the reactive cholangiocyte and the creation of a bile duct proinflammatory microenvironment. The host factors likely depend on genetic susceptibility, epigenetics, posttranscriptional regulation, or other yet unknown mechanisms, may lead to repair/resolution or to chronic inflammation of the bile ducts when the initial inflammatory response is perpetuated. Cholangiopathy ultimately results in cholestasis, bile duct proliferation, ductopenia, fibrosis, and potential malignant transformation (Fig. 2). ${ }^{6}$

\section{EXPERIMENTAL MODELS}

Our understanding of cholangiocyte biology is linked to advances in the methodology for studying these cells. Much research has been done in animal models, particularly using rats. Cholangiocytes selectively proliferate in response to various in vivo methods such as bile duct ligation, dietary manipulation, and partial hepatectomy. This allows for cholangiocytes to be harvested for further studies. Another advanced method has been the isolation of intact bile duct units. This method anables in vitro transport studies to be performed. Finally, having cultures of either normal or malignant cholangiocytes allow cell biologic studies to be performed. ${ }^{21-24}$

\section{THE MECHANISMS OF DUCTAL BILE FORMATION}

As mentioned earlier, cholangiocytes can contribute up to $40 \%$ of the daily bile output. In the bile duct ligated rat model, it was shown that cholangiocytes increased their secretory ability. Fig. 3 shows some of the important pathways that mediate secretory functions of cholangiocyte. Secretin initiates bile formation by binding to its receptor on the basolateral membrane and activating the cyclic adenosin mono-phpsphate (cAMP) signaling pathway. cAMP is important for activating apical chloride channels, which are believed to be cystic fibrosis transmembrane conductance regulator.

This efflux of chloride ions drives bicarbonate secretion by activating the chloride/bicarbonate exchanger, called AE2. An important component of cholangiocyte secretion is water, and specific water channels called aquaporins have been identified. Aquaporin 1 resides in intracellular vesicles and is stimulated by cAMP to migrate to the apical membrane. In the active state, it mediates water efflux from the cell, and somatostatin acts to inhibit this process. A separate water channel, aquaporin 4, is located on the basolateral side, but its secretory function is

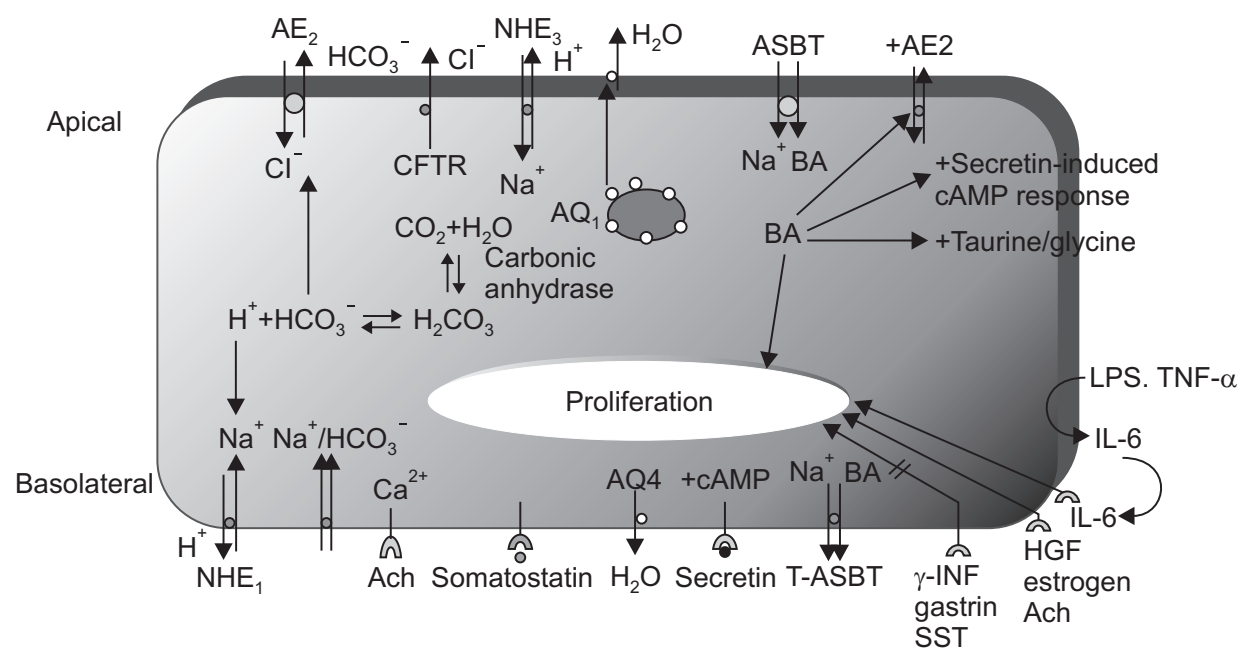

Fig. 3. Membrane transporters/receptors/channel proteins in cholangiocytes. ${ }^{1,53-55}$ The choleretic effect of secretin is mediated by increases in cAMP, the activation of cAMP-dependent $\mathrm{Cl}^{-}$channels (CFTR), and the subsequent ductal secretion of bicarbonate. Aquaporin water channels (regulated by secretin) appear to play an important role in this process. cAMP-dependent $\mathrm{Cl}^{-}$secretion enables the mobilization of intracellular $\mathrm{Ca}^{2+}$ stores and the activation of $\mathrm{Ca}^{2+}$-dependent apical membrane $\mathrm{Cl}^{-}$channels. The NHE1 isoform regulates secretin-stimulated ductal secretion. Numerous hormone/peptide receptors have been identified on the basolateral domain of cholangiocytes. Several of these receptors (VIP and bombesin) modulate ductal choleresis, whereas other receptors (gastrin and somatostatin) inhibit basal and secretin-stimulated choleresis. The apically located ABAT enables the entry of bile salts into cholangiocytes, whereas the truncated form of ABAT eliminates bile salts from the basolateral membrane.

$\mathrm{AE}$, anion exchanger; CFTR, cystic fibrosis transmembrane conductance regulator; NHE, sodium-hydrogen exchanger; ASBT, apical sodiumdependent bile acid transporter; cAMP, cyclic adenosin mono-phpsphate; LPS, lipopolysaccharide; TNF, tumor necrosis factor; IL, interleukin; HGF, hepatocyte growth factor; Ach, acetylcholine; INF, interferon; SST, somatostatin; VIP, vasoactive intestinal peptide; ABAT, apical bile acid transporter. 
much less than that of apical aquaporin 1. 6,7,25-29

Cholangiocytes contribute to the alkalinity of bile by secreting bicarbonate. Apart from CFTR and the anion exchanger previously mentioned, there are sodium/hydrogen exchangers on the basolateral and apical surface of the cholangiocyte. In addition, a sodium/bicarbonate symport mechanism exists at the basolateral surface (Fig. 3). ${ }^{6,730}$ Bicarbonate can be converted to carbonic acid, and through the action of carbonic anhydrase, it can be converted to carbon dioxide and water. Bicarbonate efflux from the cell occurs predominantly via the apical anion exchanger. Bicarbonate efflux by secretin is responsive to acetylcholine, which increases by intracellular calcium.

\section{HEPATODUCTAL COMMUNICATION: THE ROLE OF ATP}

How do hepatocytes communicate with cholangiocytes? An emerging theory is that 5'-adenosine triphosphate (ATP) and other purines are involved in signaling between these two cell types. ATP is secreted by both hepatocytes and cholangiocytes, and its binding to purinergic receptors initiates the secretory processes outlined earlier, including the secretion of choloride and of bicarbonate. ATP acts as both an autocrine and a paracrine regulator of bile flow in intrahepatic bile ducts. ${ }^{31,32}$

\section{IONIC CHANNEL ORGANIZATION WITHIN THE CHOLANGIOCYTE PLASMA MEMBRANE}

Due to the presence of numerous ion channels, the communication and coordination between these plasma membrane proteins is another area of investigation. The concept is emerging that ion channels (and perhaps other integral membrane proteins) are arranged in multiprotein complexes that allow for a coordinated function. A family of linker proteins called ezrinradixin-moesin (ERM) proteins have PDZ (post synaptic density protein [PSD95], drosophila disc large tumor suppressor [Dlg1], and zonula occludens-1 protein [zo-1]) binding domains that allow for protein-protein interactions to take place. These PDZ binding domains allow the C-termini of integral membrane proteins to bind to EBP50, which in turn binds to an ERM protein such as ezrin. When bound to the cAMP-sensitive protein, kinase A, the ERM protein brings the kinase close to its target. ERM proteins also bind to actin, which promotes the formation of a cytoskeleton scaffold for these multiprotein complexes. In summary, these linker proteins provide a coordinated function by bringing different ion channels in close proximity to each other and to regulatory proteins. ${ }^{33}$

\section{BILE ACID TRANSPORT IN CHOLANGIOCYTES (THE CHOLEHEPATIC SHUNT)}

Another important function of cholangiocytes is their role in bile acid transport. Cholangiocytes are exposed to high concentrations of bile on their apical side, and bile acids have been known to stimulate bile flow. There is now evidence of the existence of a cholehepatic shunt pathway that allows for the transport of bile acid back to the liver. The apical sodiumdependent bile acid transporter (ASBT, which is the same as the ileal bile acid transporter) has been identified on the apical membrane of cholangiocytes. ASBT transports bile acids into cholangiocytes where they can have multiple effects. They can stimulate a secretin-induced cAMP secretory response as well as stimulate bicarbonate secretion. They can be conjugated with taurine or glycine; and they can have proliferative effects on the cell. A truncated form of the ASBT has been identified on the basolateral membrane, and the existence of another sodiumindependent bile acid transporter on the basolateral membrane has been identified. The machinery exists in the cholehepatic shunt pathway in order to absorb bile acids and transport them back to the liver. ${ }^{34,35}$

\section{MORPHOLOGICAL AND FUNCTIONAL HETEROGENEITY OF CHOLANGIOCYTES}

Another important concept that has emerged is the morphological and functional heterogenecity of cholangiocytes. Small cholangiocytes, taken from bile ducts less than $15 \mathrm{mi}-$ crons in diameter, look and behave very differently from large cholangiocytes, which are taken from bile ducts larger than 15 microns. Small cholangiocytes are cuboidal, but the larger cholangiocytes are more columnar. Moreover, small cholangiocytes have inconspicuous organelles and minimal cytoplasm, whereas large cholangiocytes have plenty of organelles and a small nucleus/cytoplasm ratio. The large, but not the small, cholangiocytes have cilia. Small and large cholangiocytes differentially express the array of receptors, enzymes and transporters. More is known about the function of large cholangiocytes. Large cholangiocytes are characterized by the expression of CFTR, the anion exchanger, the bile acid transporter, the secretin receptor and proliferative response to bile duct ligation. However, small cholangiocytes do not have a hormone regulated ductal secretory response, do not respond to bile duct ligation, and are resistant to carbon tetrachloride. Small cholangiocytes are more resistant to injury: when animals are intoxicated with $\mathrm{CCl}_{4}$, large cholangiocytes undergo apoptosis, whereas small cholangiocytes proliferate, in a sort of a compensatory attempt. Small cholangiocytes can be express the secretin receptor and exhibit a secretin-induced cAMP response following the death of large cholangiocytes in animal experiment with $\mathrm{CCl}_{4} \cdot{ }^{36-38}$

\section{CHOLANGIOCYTE PROLIFERATION}

Cholangiocyte proliferation can be induced by multiple pathways. We have already mentioned that cholangiocyte is a proliferative response to bile acids. Additionally, acetylcholine, 
estrogen, hepatocyte growth factor, and IL-6 all can signal via specific receptor binding, which leads to the proliferation. For IL-6, there appears to be an autocrine loop that can be initiated by proinflammatory cytokines such as TNF- $\alpha$, and by bacterial products like lipopolysaccharide (LPS). There are antiproliferative mediators as well. Somatostatin, gastrin, and interferon $\gamma$ (IFN- $\gamma$ ) are some of the known antiproliferative agents. ${ }^{39,40}$

Stem cells in the peribiliary glands that can differentiate into cholangiocytes may be involved in biliary remodeling and pathogenesis of cholangiopathies. ${ }^{11,12}$

\section{CHOLANGIOCYTE APOPTOSIS}

Cholangiocytes can die by programmed cell death, or apoptosis. The Fas/Fas ligand system activates apoptosis in cholangiocytes, which are capable of expressing both the receptor and the ligand. This pathway may be important in PBC. The protozoan, Cryptosporidium parvum also initiates apoptosis through this pathway. Glycoursodeoxycholic acid inhibits apoptosis by blocking a key protease called caspase 3. The balance between the pro-apoptotic BAX and the antiapoptotic bcl-2 also determines whether a cell lives or dies. Carbon tetrachloride can poison cells by initiating programmed cell death. Finally, blockade of the estrogen receptor causes programmed cell death. Under- standing these pathways is important, not only for certain infections such as that due to $C$. parvum, but also because insights into these cellular mechanisms allow us to better understand vanishing bile duct syndromes, such as PBC and GVHD. ${ }^{41,42}$

\section{IMMUNOBIOLOGY OF CHOLANGIOCYTES}

The biliary tract excretes bile into the duodenum and communicates with the gastrointestinal tract. Microorganisms present in the duodenum can cause ascending infections of the biliary tract. ${ }^{6,7,43,44}$

The immunobiology of the cholangiocyte is another area of intense investigation due to the importance of immune-mediated mechanisms in vanishing bile duct syndromes, infection and inflammation. Cholangiocytes participate in the immune pathogenesis of both infectious and noninfectious hepatobiliary diseases and they play an important role in both innate and adaptive immunity. Recognition of pathogen-associated molecular patterns by Toll-like receptors leads to the secretion of antimicrobial peptides, inflammatory cytokines, and the expression of adhesion molecules that allow for an interplay between the innate and adaptive immune responses. ${ }^{6,43}$

Cholangiocytes express adhesion molecules, which allow their interaction with $\mathrm{CD}^{+}$and $\mathrm{CD}^{+}{ }^{+}$cells. ${ }^{44,45}$ Cholangiocytes

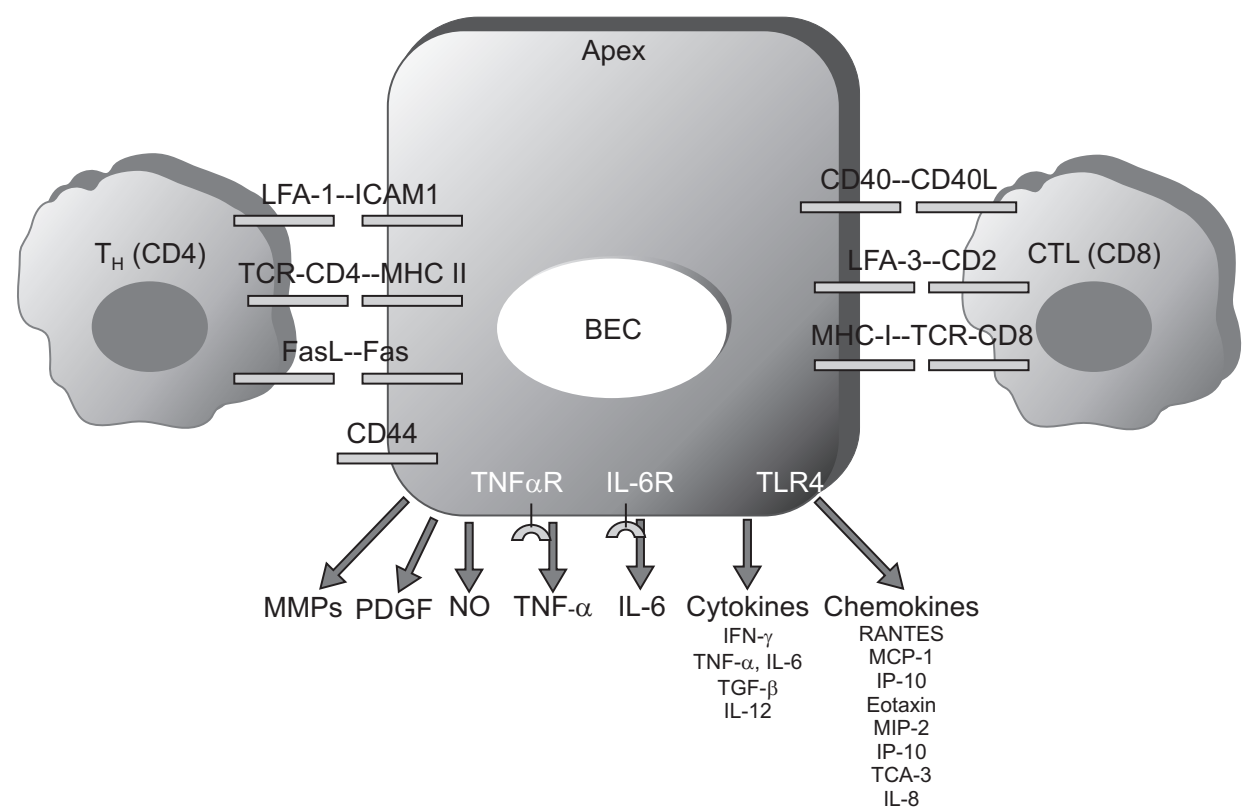

Fig. 4. Immune properties of cholangiocytes. ${ }^{44}$ Cholangiocytes express adhesion molecules, which enable their interaction with $\mathrm{CD} 4^{+}$and $\mathrm{CD} 8^{+}$ $\mathrm{T}$ cells. Because of the expression of major histocompatibility complex (MHC)-I and MHC-II on their surface, cholangiocytes are cytotoxic targets and/or antigen-presenting cells (APCs). Cholangiocytes produce chemokines and cytokines, which have autocrine or paracrine effects and modulate immune reactions. In addition, cholangiocytes secrete metalloproteinases, nitric oxide, and other growth factors involved in immune injury and fibrogenesis of the liver.

LFA, lymphocyte function-associated antigen; TCR, T-cell receptor; BEC, biliary epithelial cell; CTL, cytotoxic T lymphocyte; MMP, matrix metalloproteinase; PDGF, platelet-derived growth factor; NO, nitric oxide; TNF, tumor necrosis factor; IL, interleukin; IFN, interferon; TGF, transforming growth factor; MCP, monocyte chemotactic protein; IP-10, interferon-inducible protein-10; MIP-2, macrophage inflammatory protein-2; TCA, Tcell activation gene-3. 
can also communicate directly with lymphocytes, such as the $\mathrm{T}$ helper subsets, or cytotoxic $\mathrm{T}$ lymphocytes. The presentation of antigens on major histocompatibility complex (MHC) class I and MHC class II molecules by cholangiocytes in disease states such as PBC has been demonstrated; however, there is some controversy regarding whether cholangiocytes are true antigen presenting cells. The presence of adhesion molecules such as intercellular cell adhesion molecule 1 and lymphocyte functionassociated antigen-3 allows for direct cell-cell contact between cholangiocytes and lymphocytes, suggesting that cholangiocytes play a direct role in the immune response (Fig. 4). ${ }^{46-49}$ We have already mentioned the ability of these cells to secrete and respond to cytokines-examples given here are IL-6 and TNF- $\alpha$. $^{50}$

Cholangiocytes produce chemokines and cytokines, ${ }^{50}$ which modulate immune reactions through either autocrine or paracrine effects. In addition, cholangiocytes secrete metalloproteinases, nitric oxide (NO), and other growth factors involved in injury and in fibrogenesis of the liver (Fig. 4). ${ }^{44}$

Cholangiocytes communicate and interact with other cells in the liver. ${ }^{51}$ Reactive cholangiocytes secrete mediators and immune factors that stimulate and activate several cellular subtypes. Cholangiocytes produce IL-1, IL-6, IL-8, and IFN- $\gamma$, which regulate the immune activity of polymorphonuclear cells, Kupffer cells, and T cells. ET-1, platelet-derived growth factor $\mathrm{BB}$, transforming growth factor $\beta 2,{ }^{51}$ connective tissue growth factor, and NO and produced by cholangiocytes and stimulate subepithelial stellate cells or myofibroblasts, leading to reparative processes and/or fibrosis in the liver. ${ }^{44,45,51}$

\section{CHOLANGIOCYTE VERSATILITY: ESPECIALLY CHOLESTEROL METABOLISM}

Table 2 emphasizes the variety of roles that cholangiocytes play. This list highlights not only the complexity of these cells, but also serves as a reminder of how little we truly know about them. Cholangiocytes are versatile cells involved in secretory and absorptive functions that modify the composition of bile. Cholangiocytes express proteins involved in drug or xenobiotics metabolism, cholesterol biosynthesis and transport, mucin secretion, glucose transport, and apolipoprotein synthesis. ${ }^{1,2,13}$ The role of these proteins was well known for a long time, therefore I will not be mentioning the role of those proteins in this review. Recently cholesterol transporters and nuclear hormone receptors associated lipid metabolism investigated in many studies.

Bile contains cholesterol, and thus the concentration of bile within the gallbladder results in high cholesterol levels in this organ. ${ }^{52,53}$ This facilitates cholesterol gallstone formation and cholesterolosis of the gallbladder wall. ${ }^{54,55}$ GBECs are exposed to high and fluctuating biliary cholesterol concentrations on their apical surfaces. They absorb biliary cholesterol via both passive and active mechanisms, ${ }^{56,57}$ but the fate of this absorbed cholesterol is unclear. Cholesterol release from peripheral tissues, pri- marily from macrophage-derived foam cells, is the first step in a process called "reverse cholesterol transport." 58,59 In this pathway, excess cholesterol present in peripheral tissue cells is incorporated into high density lipoproteins, which deliver the excess cholesterol to the liver for excretion, either directly or indirectly by transfer to low density lipoprotein. ${ }^{60}$ A number of different mechanisms participate in transporting cholesterol from cells to extracellular acceptor lipoproteins. These cholesterol efflux pathways include unmediated diffusion ${ }^{61}$ and protein mediated transport by scavenger receptor BI or ATP-binding cassette transporter A1 (ABCA1). ${ }^{62,63}$ ATP binding cassette transporter G5 and ABCG8 form heterodimers that are expressed on the canalicular membranes of hepatocytes, where they excrete cholesterol into bile. ${ }^{64,65}$ It has been suggested that ABCG5/ABCG8 play a role in sterol flux at the apical pole of polarized epithelial cells in the liver. The unloading of cellular cholesterol onto cholesterol acceptors ${ }^{66}$ is also likely to be important in maintaining cholesterol homeostasis within the gallbladder wall and in the gallbladder lumen. The relative contributions of basolateral and apical disposition of cholesterol by GBECs is likely to be important in determining aberrant cholesterol disposition in the wall

Table 2. Cholangiocyte Versatility ${ }^{53-55,70}$

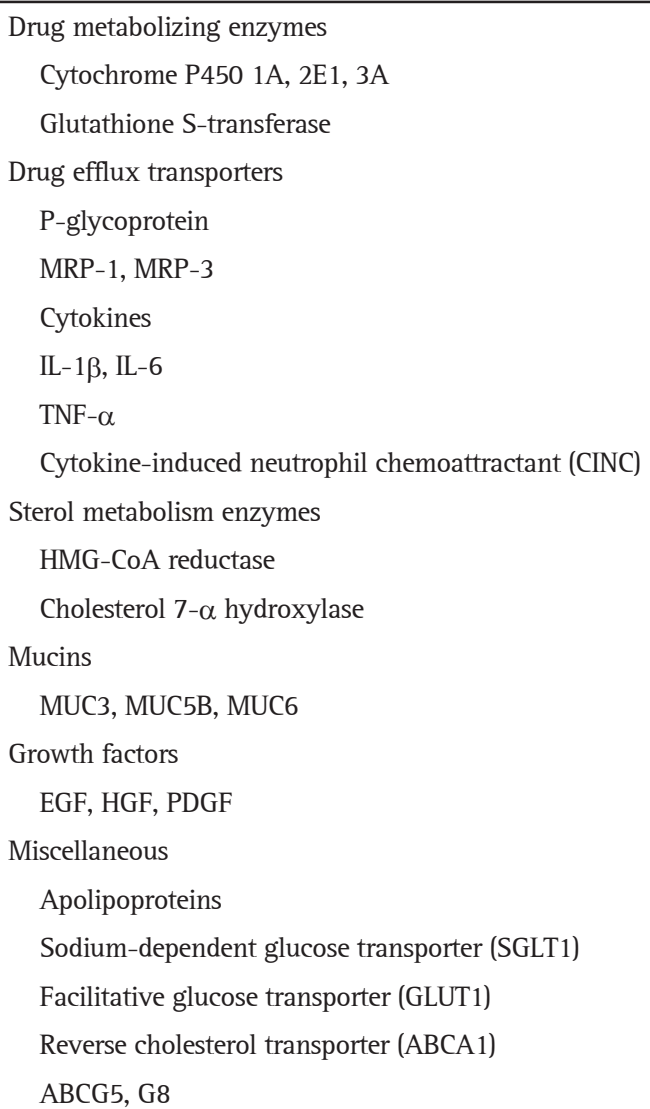

MRP, multidrug resistance protein; IL, interleukin; TNF; tumor necrosis factor; HMG, 3-hydroxy-3-methylglutaryl; MUC, mucin; EGF, epidermal growth factor; HGF, hepatocyte growth factor; PDGF, plateletderived growth factor; ABCG, ATP binding cassette transporter G. 
and lumen of gallbladder. It has been previously reported that ABCA1 is expressed on the basolateral membranes of cultured dog GBECs, where it mediates cholesterol efflux via a liver $\mathrm{X}$ receptor a/retinoid X receptor ligand-sensitive mechanism. ${ }^{55,67,68}$

The mechanisms involved in apical cholesterol flux in gallbladder epithelium are unknown, but are likely to involve ABCG5/ABCG8. ${ }^{53,54}$ Little is known regarding the existence and function of ABCA1, ABCG5, and ABCG8 in human GBECs. The sterol transporters $\mathrm{ABCA} 1, \mathrm{ABCG} 5$, and $\mathrm{ABCG} 8$ may play a role in the pathogenesis of human cholesterol associated gallbladder diseases. Inflammation appears to be a key factor that increases ABCA1 expression and activity in the human gallbladder. ${ }^{53,54,69,70}$

In addition, it also has been demonstrated that ligands of peroxisome proliferator-activated receptor modulate inflammation and affect ABCA1 expression in GBEC. This evidence suggests that GBECs have a perfect system for cholesterol transport. ${ }^{71-73}$

\section{CLINICAL IMPLICATIONS}

Cholangiopathies are heterogeneous etiology, but share two major features: (1) dysregulated balance between cell proliferation and survival; (2) selectively target either small or large bile ducts. The two most common cholangiopathies are PBC and PSC. $^{74}$

Cholangiocyte heterogeneity that two different (small and large) cholangiocyte subpopulations exist, which differ in morphological and biological aspects. Cholangiopathies target either small or large bile ducts. ${ }^{74}$

Cholangiocyte functional activity is regulated by secretin, which induces $\mathrm{HCO}_{3}{ }^{-}$in bile by the activation of the AE2 exchanger. AE2 knockout animals develop a PBC-like phenotype. A variant of the AE2 gene discriminate patients with slower progression of $\mathrm{PBC}$. $^{7,10,13}$

Cholangiocyte biology and response to injury is regulated by bile acids in conditions of cholestasis and ductopenia, bile acids exert cytoprotective effects. Exacerbation of liver injury is observed in models of PSC-like cholestasis. Ursodeoxycholic acid (UDCA) is the only compound to show some effects in PBC, whereas limited effects are observed in PSC. Alternative therapies for cholestatic liver diseases is required. Two bile acids derivatives as obeticholic acid (OCA) and nor-ursodeoxycholic acid (nor-UDCA) show promising results recently. ${ }^{75}$

OCA is a semisynthetic analogue of chenodeoxycholic acid that possesses a strong farnesoid X receptor (FXR) affinity. Endogenous bile acids bind to FXR, which in turn represses or induces the expression of various genes involved in their synthesis and secretion, such as cytochrome P450 7A1 (CYP7A1), bile salt export pump, and sodium-taurocholate cotransporting polypeptide. Chenodeoxycholic acid is the most potent endogenous FXR ligand (with a 100-fold less affinity than OCA) whereas UDCA has no affinity. ${ }^{76,77}$

Nor-UDCA, a C(23) homologue of UCDA, which is novel candidate for the therapy of cholangiopathies able to ameliorate sclerosing cholangitis in Mdr2 knockout mice. Nor-UDCA actions are following: increased hydrophilicity of bile acids; stimulated bile flow with flushing of injured bile ducts, and detoxification and elimination routes for bile acids. ${ }^{78,79}$

Cholangiocytes express both adrenergic and cholinergic receptors. The autonomic innervation: (1) sustains cholangiocyte proliferation and prevent apoptosis in response to injury; (2) maintain an adequate bile acids transporter (ASBT) in cholangiocytes. Development of non-anastomotic biliary strictures in the transplanted liver occurs as a consequence of impaired hepatocellular transporters. $^{74,75}$

Cholangiocytes express estrogen receptors, which exert cytoprotective effects and sustain their response to injury. PBC is more frequent in women, and its clinical breakthrough is often after menopause. Estrogen receptor expression is markedly reduced in late stage $\mathrm{PBC}^{80-82}$

Reactive cholangiocytes synthesize and locally release endogenous opioid peptides, which inhibit their biological response to injury. Endogenous opioid peptides contribute to the genesis of pruritus in cholestatic patients; the administration of opiateantagonists is effective in reducing pruritus in those patients. ${ }^{83-85}$

Reactive cholangiocytes synthesize and locally release serotonin, which inhibits their biological response to injury. Administration of sertraline resulted effective in ameliorating pruritus in patients with PBC. Altered response to the activation serotonin receptors is malignant cholangiocytes. ${ }^{83,86-88}$

Cholangiocyte release IGF-1 and VEGF in response to injury; they stimulate cholangiocyte biological response to injury. IGF1 and VEGF stimulate cholangiocarcinoma cell growth. VEGF allows the expansion of the PBP (peribiliary vascular plexus). Progression of PBC and PSC is associated with an upcoming reduction of the PBP around bile ducts. Antiangiogenic therapies may be effective in cholangiocarcinoma. Measurement of biliary IGF-1 levels in patients with biliary strictures discriminate between cholangiocarcinoma and other causes of biliary obstruction. $^{89-91}$

The activation of the GLP-1 receptor in cholangiocytes sustain proliferation and prevents apoptosis. GLP-1 analogues are available as novel tools in the therapy of diabetes in humans. Possible effects in preventing bile duct loss observed in PBC patients. $^{92}$

In response to bacterial products, auto-antibodies and cytokines, cholangiocytes express adhesion molecule and release leuco-attractant cytokines. Cytokines impair cholangiocyte functions. In the course of cholangiopathies, cholangiocytes are exposed to bacterial products like LPS or auto-antibodies. ${ }^{93-95}$

Monoclonal antibodies is a possible therapeutic tool to treat cholangiopathies. ${ }^{96}$ Rituximab has been tested in six PBC patients who have an incomplete response to UDCA. ${ }^{97}$ Based on genetic association between the IL-2, IL-23 pathways and PBC, ${ }^{98,99}$ ustekinumab, an anti-p40 monoclonal antibody is cur- 
rently under way.

BTT1023 is a human monoclonal antibody targeting the vascular adhesion protein-1, a molecule that has been shown to stimulate the recruitment of effector lymphocytes to the liver through the upregulation of the endothelial cell adhesion molecule MadCAM-1. ${ }^{100,101}$ Simtuzumab is directed against the lysyl oxidase-like protein 2, an enzyme that favors the cross-linking of collagen and elastin fibers. ${ }^{102}$ These two monoclonal antibodies are investigated in PSC patients.

\section{CONCLUSIONS}

An overview of the current state of knowledge regarding the biology of the cholangiocyte has been summarized in this review. Cholangiocytes are versatile cells involved in transport processes that modify the composition and volume of bile. Cholangiocytes undergo proliferation and programmed cell death in response to certain stimuli, and they are functionally and morphologically heterogeneous. Finally, cholangiocytes participate in multiple immune responses. All of these cholangiocyte functions are relevant, because they provide insight into the pathophysiology of cholangiopathies.

\section{CONFLICTS OF INTEREST}

No potential conflict of interest relevant to this article was reported.

\section{ACKNOWLEDGEMENTS}

The authors would like to thank Prof. Rahul Kuver for contributing his extensive knowledge and preparing some figures for this review.

\section{REFERENCES}

1. Alpini G, McGill JM, Larusso NF. The pathobiology of biliary epithelia. Hepatology 2002;35:1256-1268.

2. Strazzabosco M, Spirlí C, Okolicsanyi L. Pathophysiology of the intrahepatic biliary epithelium. J Gastroenterol Hepatol 2000;15: 244-253.

3. Roberts SK, Ludwig J, Larusso NF. The pathobiology of biliary epithelia. Gastroenterology 1997;112:269-279.

4. Tietz PS, Larusso NF. Cholangiocyte biology. Curr Opin Gastroenterol 2006;22:279-287.

5. Strazzabosco M, Fabris L, Spirli C. Pathophysiology of cholangiopathies. J Clin Gastroenterol 2005;39(4 Suppl 2):S90-S102.

6. Lazaridis KN, LaRusso NF. The cholangiopathies. Mayo Clin Proc 2015;90:791-800

7. Lazaridis KN, Strazzabosco M, Larusso NF. The cholangiopathies: disorders of biliary epithelia. Gastroenterology 2004;127:15651577.
8. Bogert PT, LaRusso NF. Cholangiocyte biology. Curr Opin Gastroenterol 2007;23:299-305.

9. Alvaro D, Mancino MG, Glaser S, et al. Proliferating cholangiocytes: a neuroendocrine compartment in the diseased liver. Gastroenterology 2007;132:415-431.

10. Marzioni M, Glaser SS, Francis H, Phinizy JL, LeSage G, Alpini G. Functional heterogeneity of cholangiocytes. Semin Liver Dis 2002;22:227-240.

11. Cardinale V, Wang Y, Carpino G, et al. Multipotent stem/progenitor cells in human biliary tree give rise to hepatocytes, cholangiocytes, and pancreatic islets. Hepatology 2011;54:2159-2172.

12. Carpino G, Cardinale V, Onori P, et al. Biliary tree stem/progenitor cells in glands of extrahepatic and intraheptic bile ducts: an anatomical in situ study yielding evidence of maturational lineages. J Anat 2012;220:186-199.

13. Desmet VJ. Vanishing bile duct disorders. Prog Liver Dis 1992;10: 89-121.

14. Sirica AE. Biology of biliary epithelial cells. Prog Liver Dis 1992; 10:63-87.

15. Onori P, Franchitto A, Alvaro D, Gaudio E. Immunohistochemical features of bile duct epithelial cells in normal and experimental liver conditions. Ital J Anat Embryol 2001;106(2 Suppl 1):371378.

16. Nakanuma Y, Tsuneyama K, Harada K. Pathology and pathogenesis of intrahepatic bile duct loss. J Hepatobiliary Pancreat Surg 2001;8:303-315.

17. Liu Z, Sakamoto T, Yokomuro S, et al. Acute obstructive cholangiopathy in interleukin-6 deficient mice: compensation by leukemia inhibitory factor (LIF) suggests importance of gp-130 signaling in the ductular reaction. Liver 2000;20:114-124.

18. Reynoso-Paz S, Coppel RL, Ansari AA, Gershwin ME. Vanishing bile duct syndromes: considerations of the immunobiology of autoimmune biliary diseases. Isr Med Assoc J 1999;1:37-44.

19. O'Hara SP, Tabibian JH, Splinter PL, LaRusso NF. The dynamic biliary epithelia: molecules, pathways, and disease. J Hepatol 2013;58:575-582.

20. Desmet VJ. Ductal plates in hepatic ductular reactions. Hypothesis and implications. I. Types of ductular reaction reconsidered. Virchows Arch 2011;458:251-259.

21. Tietz PS, Chen XM, Gong AY, et al. Experimental models to study cholangiocyte biology. World J Gastroenterol 2002;8:1-4.

22. Masyuk TV, Ritman EL, LaRusso NF. Quantitative assessment of the rat intrahepatic biliary system by three-dimensional reconstruction. Am J Pathol 2001;158:2079-2088.

23. Khaoustov VI, Darlington GJ, Soriano HE, et al. Induction of three-dimensional assembly of human liver cells by simulated microgravity. In Vitro Cell Dev Biol Anim 1999;35:501-509.

24. Joplin R. Isolation and culture of biliary epithelial cells. Gut 1994;35:875-878.

25. Splinter PL, Masyuk AI, Marinelli RA, LaRusso NF. AQP4 transfected into mouse cholangiocytes promotes water transport in biliary epithelia. Hepatology 2004;39:109-116. 
26. Shibao K, Hirata K, Robert ME, Nathanson MH. Loss of inositol 1,4,5-trisphosphate receptors from bile duct epithelia is a common event in cholestasis. Gastroenterology 2003;125:1175-1187.

27. Baiocchi L, Alpini G, Glaser S, et al. Taurohyodeoxycholate- and tauroursodeoxycholate-induced hypercholeresis is augmented in bile duct ligated rats. J Hepatol 2003;38:136-147.

28. Feranchak AP, Sokol RJ. Cholangiocyte biology and cystic fibrosis liver disease. Semin Liver Dis 2001;21:471-488.

29. Feranchak AP, Roman RM, Doctor RB, Salter KD, Toker A, Fitz JG. The lipid products of phosphoinositide 3-kinase contribute to regulation of cholangiocyte ATP and chloride transport. J Biol Chem 1999;274:30979-30986.

30. Melero S, Spirli C, Zsembery A, et al. Defective regulation of cholangiocyte $\mathrm{Cl}-/ \mathrm{HCO} 3(-)$ and $\mathrm{Na}+\mathrm{H}+$ exchanger activities in primary biliary cirrhosis. Hepatology 2002;35:1513-1521.

31. Feranchak AP, Fitz JG. Adenosine triphosphate release and purinergic regulation of cholangiocyte transport. Semin Liver Dis 2002;22:251-262.

32. Roman RM, Feranchak AP, Salter KD, Wang Y, Fitz JG. Endogenous ATP release regulates $\mathrm{Cl}$ - secretion in cultured human and rat biliary epithelial cells. Am J Physiol 1999;276(6 Pt 1):G1391G1400.

33. Zsembery A, Spirli C, Granato A, et al. Purinergic regulation of acid/base transport in human and rat biliary epithelial cell lines. Hepatology 1998;28:914-920.

34. Strazzabosco M, Joplin R, Zsembery A, et al. $\mathrm{Na}(+)$-dependent and -independent $\mathrm{Cl}-\mathrm{HCO}-3$ exchange mediate cellular HCO3transport in cultured human intrahepatic bile duct cells. Hepatology 1997;25:976-985.

35. Strazzabosco M. Transport systems in cholangiocytes: their role in bile formation and cholestasis. Yale J Biol Med 1997;70:427434.

36. LeSage GD, Benedetti A, Glaser S, et al. Acute carbon tetrachloride feeding selectively damages large, but not small, cholangiocytes from normal rat liver. Hepatology 1999;29:307-319.

37. Alpini G, Glaser SS, Ueno Y, et al. Heterogeneity of the proliferative capacity of rat cholangiocytes after bile duct ligation. Am J Physiol 1998;274(4 Pt 1):G767-G775.

38. Alpini G, Roberts S, Kuntz SM, et al. Morphological, molecular, and functional heterogeneity of cholangiocytes from normal rat liver. Gastroenterology 1996;110:1636-1643.

39. Alvaro D, Alpini G, Onori P, et al. Estrogens stimulate proliferation of intrahepatic biliary epithelium in rats. Gastroenterology 2000;119:1681-1691.

40. Park J, Gores GJ, Patel T. Lipopolysaccharide induces cholangiocyte proliferation via an interleukin-6-mediated activation of p44/p42 mitogen-activated protein kinase. Hepatology 1999;29:1037-1043.

41. Chen XM, Levine SA, Tietz P, et al. Cryptosporidium parvum is cytopathic for cultured human biliary epithelia via an apoptotic mechanism. Hepatology 1998;28:906-913.

42. Celli A, Que FG. Dysregulation of apoptosis in the cholangiopa- thies and cholangiocarcinoma. Semin Liver Dis 1998;18:177-185.

43. Syal G, Fausther M, Dranoff JA. Advances in cholangiocyte immunobiology. Am J Physiol Gastrointest Liver Physiol 2012;303:G1077-G1086.

44. Fava G, Glaser S, Francis H, Alpini G. The immunophysiology of biliary epithelium. Semin Liver Dis 2005;25:251-264.

45. Chuang YH, Lan RY, Gershwin ME. The immunopathology of human biliary cell epithelium. Semin Immunopathol 2009;31:323331.

46. Reynoso-Paz S, Coppel RL, Mackay IR, Bass NM, Ansari AA, Gershwin ME. The immunobiology of bile and biliary epithelium. Hepatology 1999;30:351-357.

47. Ueno Y, Phillips J0, Ludwig J, Lichtman SN, LaRusso NF. Development and characterization of a rodent model of immunemediated cholangitis. Proc Natl Acad Sci U S A 1996;93:216-220.

48. LaRusso NF. Morphology, physiology, and biochemistry of biliary epithelia. Toxicol Pathol 1996;24:84-89.

49. Galperin C, Gershwin ME. Immunopathology of primary biliary cirrhosis. Baillieres Clin Gastroenterol 1996;10:461-481.

50. Savard CE, Blinman TA, Choi HS, Lee SK, Pandol SJ, Lee SP. Expression of cytokine and chemokine mRNA and secretion of tumor necrosis factor-alpha by gallbladder epithelial cells: response to bacterial lipopolysaccharides. BMC Gastroenterol 2002;2:23.

51. Choi HS, Savard CE, Choi JW, Kuver R, Lee SP. Paclitaxel interrupts TGF-beta1 signaling between gallbladder epithelial cells and myofibroblasts. J Surg Res 2007;141:183-191.

52. Choi HS, Kim YW. Oxysterol (3,5-cholestadien-7-one, 5 betacholestan-3-one, 5,24-cholestadien-3 beta-OL) induced cytotoxicity and apoptosis in gallbladder epithelial cells. Korean J Gastroenterol 2004;44:328-336.

53. Yoon JH, Choi HS, Jun DW, et al. ATP-binding cassette sterol transporters are differentially expressed in normal and diseased human gallbladder. Dig Dis Sci 2013;58:431-439.

54. Tauscher A, Kuver R. ABCG5 and ABCG8 are expressed in gallbladder epithelial cells. Biochem Biophys Res Commun 2003;307:1021-1028.

55. Lee J, Shirk A, Oram JF, Lee SP, Kuver R. Polarized cholesterol and phospholipid efflux in cultured gall-bladder epithelial cells: evidence for an ABCA1-mediated pathway. Biochem J 2002;364(Pt 2):475-484.

56. Jacyna MR, Ross PE, Bakar MA, Hopwood D, Bouchier IA. Characteristics of cholesterol absorption by human gall bladder: relevance to cholesterolosis. J Clin Pathol 1987;40:524-529.

57. Neiderhiser DH, Harmon CK, Roth HP. Absorption of cholesterol by the gallbladder. J Lipid Res 1976;17:117-124.

58. Angelin B, Parini P, Eriksson M. Reverse cholesterol transport in man: promotion of fecal steroid excretion by infusion of reconstituted HDL. Atheroscler Suppl 2002;3:23-30.

59. Movva R, Rader DJ. Laboratory assessment of HDL heterogeneity and function. Clin Chem 2008;54:788-800.

60. Yancey PG, Bortnick AE, Kellner-Weibel G, de la Llera-Moya M, Phillips MC, Rothblat GH. Importance of different pathways 
of cellular cholesterol efflux. Arterioscler Thromb Vasc Biol 2003;23:712-719.

61. Rothblat GH, de la Llera-Moya M, Atger V, Kellner-Weibel G, Williams DL, Phillips MC. Cell cholesterol efflux: integration of old and new observations provides new insights. J Lipid Res 1999;40:781-796.

62. Ji Y, Jian B, Wang N, et al. Scavenger receptor BI promotes high density lipoprotein-mediated cellular cholesterol efflux. J Biol Chem 1997;272:20982-20985.

63. Lee JY, Parks JS. ATP-binding cassette transporter AI and its role in HDL formation. Curr Opin Lipidol 2005;16:19-25.

64. Wittenburg H, Carey MC. Biliary cholesterol secretion by the twinned sterol half-transporters ABCG5 and ABCG8. J Clin Invest 2002;110:605-609.

65. Yu L, Li-Hawkins J, Hammer RE, et al. Overexpression of ABCG5 and ABCG8 promotes biliary cholesterol secretion and reduces fractional absorption of dietary cholesterol. J Clin Invest 2002;110:671-680.

66. Lee J. Introduction of a model for study of polarized cholesterol and phospholipid efflux in gallbladder epithelial cells. Korean J Gastroenterol 2002;39:216-225.

67. Lee J, Tauscher A, Seo DW, Oram JF, Kuver R. Cultured gallbladder epithelial cells synthesize apolipoproteins A-I and E. Am J Physiol Gastrointest Liver Physiol 2003;285:G630-G641.

68. Lee J, Choi HS. Reverse cholesterol transport in cultured gallbladder epithelial cells. Korean J Gastroenterol 2004;43:145-152.

69. Choi HS, No NY, Lee J, et al. ABCA1 expression of human gallbladder tissue in various gallbladder diseases. Korean J Gastroenterol 2003;41(abstr):599A.

70. Choi HS. The biology of the cholangiocytes. Hanyang Med Rev 2007;27:4-12

71. Lee J. Transporters and nuclear hormone receptors associated with cholesterol metabolism in gallbladder epithelial cells. Hanyang Med Rev 2007;27:20-28.

72. Lee J, Hong EM, Byun HW, et al. The effect of PPARalpha and PPARgamma ligands on inflammation and ABCA1 expression in cultured gallbladder epithelial cells. Dig Dis Sci 2008;53:17071715.

73. Lee J, Hong EM, Koh DH, et al. HMG-CoA reductase inhibitors (statins) activate expression of PPARalpha/PPARgamma and ABCA1 in cultured gallbladder epithelial cells. Dig Dis Sci 2010;55:292-299.

74. Marzioni M, Saccomanno S, Candelaresi C, et al. Clinical implications of novel aspects of biliary pathophysiology. Dig Liver Dis 2010;42:238-244.

75. Maroni L, Haibo B, Ray D, et al. Functional and structural features of cholangiocytes in health and disease. Cell Mol Gastroenterol Hepatol 2015;1:368-380.

76. Pellicciari R, Fiorucci S, Camaioni E, et al. 6alpha-ethyl-chenodeoxycholic acid (6-ECDCA), a potent and selective FXR agonist endowed with anticholestatic activity. J Med Chem 2002;45:35693572.
77. Sinal CJ, Tohkin M, Miyata M, Ward JM, Lambert G, Gonzalez FJ. Targeted disruption of the nuclear receptor FXR/BAR impairs bile acid and lipid homeostasis. Cell 2000;102:731-744.

78. Cohen BI, Hofmann AF, Mosbach EH, et al. Differing effects of nor-ursodeoxycholic or ursodeoxycholic acid on hepatic histology and bile acid metabolism in the rabbit. Gastroenterology 1986;91:189-197.

79. Hohenester S, Wenniger LM, Paulusma CC, et al. A biliary HCO3umbrella constitutes a protective mechanism against bile acid-induced injury in human cholangiocytes. Hepatology 2012;55:173183.

80. Iwai M, Shimazu T. Alteration in sympathetic nerve activity during liver regeneration in rats after partial hepatectomy. J Auton Nerv Syst 1992;41:209-214.

81. LeSage GD, Alvaro D, Glaser S, et al. Alpha-1 adrenergic receptor agonists modulate ductal secretion of BDL rats via $\mathrm{Ca}(2+)-$ and PKC-dependent stimulation of cAMP. Hepatology 2004;40:11161127.

82. Francis H, LeSage G, DeMorrow S, et al. The alpha2-adrenergic receptor agonist UK 14,304 inhibits secretin-stimulated ductal secretion by downregulation of the cAMP system in bile ductligated rats. Am J Physiol Cell Physiol 2007;293:C1252-C1262.

83. Marzioni M, Ueno Y, Glaser S, et al. Cytoprotective effects of taurocholic acid feeding on the biliary tree after adrenergic denervation of the liver. Liver Int 2007;27:558-568.

84. Glaser S, Alvaro D, Francis H, et al. Adrenergic receptor agonists prevent bile duct injury induced by adrenergic denervation by increased cAMP levels and activation of Akt. Am J Physiol Gastrointest Liver Physiol 2006;290:G813-G826.

85. Marzioni M, Alpini G, Saccomanno S, et al. Endogenous opioids modulate the growth of the biliary tree in the course of cholestasis. Gastroenterology 2006;130:1831-1847.

86. Alvaro D, Metalli VD, Alpini G, et al. The intrahepatic biliary epithelium is a target of the growth hormone/insulin-like growth factor 1 axis. J Hepatol 2005;43:875-883.

87. Gaudio E, Barbaro B, Alvaro D, et al. Vascular endothelial growth factor stimulates rat cholangiocyte proliferation via an autocrine mechanism. Gastroenterology 2006;130:1270-1282.

88. Gaudio E, Barbaro B, Alvaro D, et al. Administration of r-VEGFA prevents hepatic artery ligation-induced bile duct damage in bile duct ligated rats. Am J Physiol Gastrointest Liver Physiol 2006;291:G307-G317.

89. Drucker DJ. Biological actions and therapeutic potential of the glucagon-like peptides. Gastroenterology 2002;122:531-544.

90. Marzioni M, Alpini G, Saccomanno S, et al. Glucagon-like peptide-1 and its receptor agonist exendin-4 modulate cholangiocyte adaptive response to cholestasis. Gastroenterology 2007;133:244255.

91. Hanada S, Harada M, Koga H, et al. Tumor necrosis factor-alpha and interferon-gamma directly impair epithelial barrier function in cultured mouse cholangiocytes. Liver Int 2003;23:3-11.

92. Spirlì C, Fabris L, Duner E, et al. Cytokine-stimulated nitric oxide 
production inhibits adenylyl cyclase and cAMP-dependent secretion in cholangiocytes. Gastroenterology 2003;124:737-753.

93. Eksteen B, Miles A, Curbishley SM, et al. Epithelial inflammation is associated with CCL28 production and the recruitment of regulatory T cells expressing CCR10. J Immunol 2006;177:593-603.

94. Karrar A, Broomé U, Södergren T, et al. Biliary epithelial cell antibodies link adaptive and innate immune responses in primary sclerosing cholangitis. Gastroenterology 2007;132:1504-1514.

95. Salas JT, Banales JM, Sarvide S, et al. Ae2a,b-deficient mice develop antimitochondrial antibodies and other features resembling primary biliary cirrhosis. Gastroenterology 2008;134:1482-1493.

96. Moritoki Y, Lian ZX, Lindor K, et al. B-cell depletion with antiCD20 ameliorates autoimmune cholangitis but exacerbates colitis in transforming growth factor-beta receptor II dominant negative mice. Hepatology 2009;50:1893-1903.

97. Tsuda M, Moritoki Y, Lian ZX, et al. Biochemical and immunologic effects of rituximab in patients with primary biliary cirrhosis and an incomplete response to ursodeoxycholic acid. Hepatology 2012;55:512-521.

98. Lleo A, Gershwin ME, Mantovani A, Invernizzi P. Towards common denominators in primary biliary cirrhosis: the role of IL-12. J Hepatol 2012;56:731-733.

99. Hirschfield GM, Liu X, Xu C, et al. Primary biliary cirrhosis associated with HLA, IL12A, and IL12RB2 variants. N Engl J Med 2009;360:2544-2555.

100. Eaton JE, Talwalkar JA, Lazaridis KN, Gores GJ, Lindor KD. Pathogenesis of primary sclerosing cholangitis and advances in diagnosis and management. Gastroenterology 2013;145:521-536.

101. Liaskou E, Karikoski M, Reynolds GM, et al. Regulation of mucosal addressin cell adhesion molecule 1 expression in human and mice by vascular adhesion protein 1 amine oxidase activity. Hepatology 2011;53:661-672.

102. Moon HJ, Finney J, Ronnebaum T, Mure M. Human lysyl oxidase-like 2. Bioorg Chem 2014;57:231-241. 